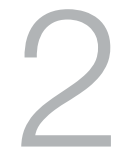

\title{
A Retrospective: The Influence of Rob Lesslie-Landscape Scientist, Geographer and Natural Resources Land Use Planner
}

Richard Thackway

\section{Key Points}

- Effective leadership in the areas of land use policy and planning involves understanding the values and ideals of others. Respected leaders engage the key players, listen well and practise diplomacy.

- The process of developing, implementing and evaluating land use policies and plans involves leaders collecting, collating and curating large amounts of relevant spatial and temporal data and information. Key leaders of land use planning programs demonstrate the value of primary data: collect once, use many times.

- Sound leadership knows how to use conceptual models that represent the real world, assisting decision-makers and other stakeholder groups to visualise complex eco-social systems, investigate and manipulate data and information, and discover and inform collective decisionmaking (e.g. what is now, what could be and what can be). 
- Developing realistic scenarios of alternative or different social, economic and environmental outcomes, both in space and time, requires leaders with humility and strength. Influential leaders participate in the planning process and are true to their core principles.

- Promoting long-term sustainable management and conservation of Australia's national landscapes and ecosystems involves influencing future leaders now; influential leaders are generous with their resources, including philanthropy.

These key lessons are discussed via a retrospective of the influence of Dr Robert George Lesslie-landscape scientist, geographer and natural resources land use planner. Among Rob's many interests and passions was his desire to identify and preserve the wild places and undisturbed natural areas of Australia. I learned about this passion over a 20 -year period, as we periodically walked and talked. Rob's contributions to the fields of land use policy and planning were impressive. This retrospective presents representative examples of his life's work.

Robert George Lesslie was born in Sydney on 25 February 1957; he lived in Adelaide and Canberra, which is where he died on 28 March 2014. Emeritus Professor Henry Nix observed:

Future generations will come to value his research contributions to key questions of conservation, land management and sustainability. Rob was just reaching the pinnacle of his creative contributions and Australia and the world is the poorer for his loss (Henry Nix, personal communication).

Rob's career spanned more than 30 years; he worked in natural resources evaluation and management in government, education and the private sector. Throughout his career, he published numerous book chapters, journal articles and technical reports. He was a sought-after speaker at conferences and workshops. However, Rob's influence went well beyond this, as he was also significantly involved in the formulation and implementation of pressing natural resource management policies.

I first met Rob in the late 1980s when I was appointed an advisor on the Australian Government Scientific Review Committee, convened to evaluate the National Wilderness Mapping Project. From that time on, our paths crossed regularly on various projects, including vegetation condition, land management and rangeland management, ecosystem services and the potential to combine geographic information 
systems (GIS) and Bayesian belief networks for environmental assessment and classification based on the vegetation assets, states and transitions (VAST) framework.

Rob's tertiary studies and research focused on how humans interact with the environment and the effects of use and management of (Australia's) landscapes. He gained a Bachelor of Arts from Macquarie University in 1978, majoring in geography and economics, and a Master of Environmental Studies from the University of Adelaide in 1982. In 1997, he was awarded a PhD from The Australian National University for his thesis entitled 'A spatial analysis of human interference in terrestrial environments at landscape scales'.

Rob profoundly influenced both the assessment and mapping of land use and ecological condition and the use of this information in the development of land use policy, natural resource management and conservation in Australia. I am grateful to have learned the following key lessons from him.

\section{Practise Diplomacy}

Rob's ability to develop genuine relationships in the course of his professional associations was outstanding. Easygoing and easy to get along with, he was widely valued as a friend. Staff and colleagues commented that they felt he took a real interest in their work and that he listened carefully to them and genuinely considered the matters they raised. These characteristics travelled with him-in intergovernmental meetings, sectoral meetings with industry, his interactions with government officials and scientific debates - and he demonstrated a respect for others. As a result, he was welcomed and valued in these spheres.

Rob's character was clearly expressed through his involvement in and coordination of the Australian Collaborative Land Use and Management Program (ACLUMP, 2010; National Land and Water Resource Audit [NLWRA], 2008). A partnership between state, territory and federal government land management agencies, the program provides consistent land use information across the whole continent. Partners contribute to broader national understandings on a wide range of natural resource management (NRM) subjects, including the management and protection of native vegetation, water and soil conservation and production, and the control of weeds and pest animals. This involves working together to 
establish national guidelines for nationally consistent land use mapping coverage for Australia at 'continental' and 'catchment' scales; developing a national information system for land management practices- the 'how' of land use; developing agreed national technical standards, including the Australian Land Use and Management Classification; developing a national land use data directory and the maintenance of land use datasets on federal and state government data repositories; and developing regional and national systems for reporting land use and land management practices (NLWRA, 2008).

Before Rob began coordinating ACLUMP, each member agency had disparate ways of measuring and collecting land use data; there was no means by which an overall understanding of Australian land use practices could be assessed and reported, or an Australia-wide land use map produced.

Gaining the support of Australia's various state and federal land management agencies required considerable diplomacy; it called for someone committed to collaboration and with a strong sense of fairnesssomeone of integrity, generosity, commitment and humility: Rob. Rob's ability to gain support and achieve consensus among various parties grew out of his respect for the different roles and responsibilities of state and federal agencies within a national context. He was able to identify common strategies and priorities that facilitated joint investment in a collaborative land use mapping program. The cohesion of the partnership was due, in no small measure, to Rob's considerable intellectual and people-based aptitude.

One of the few surviving national coordinating committees, ACLUMP is recognised as an exemplar in cross-jurisdictional natural resource coordination. Rob supported a culture of regular meetings in which land use policy and planning issues could be openly discussed. Such issues included how industry sectors might better contribute to national ecological sustainable development, the need for common land use classification frameworks to enable the analysis of information to meet immediate and emerging policy issues, and the need to investigate new technologies so that changes in land use and the environmental effects could be more rapidly monitored.

Rob's insights and writings continue in the work and research of other individuals across Australia. His commitment to land use policy and planning is seen in others who are now fostering and promoting the 
collection and dissemination of nationally consistent land use and land management practices data and information. It is also reflected by those who recognise the benefits of working with key decision-makers to use information to influence land use policy and planning decisions.

\section{Demonstrate the Value of Primary Data: Collect Once, Use Many Times}

In relation to the Australian National Wilderness Inventory (ANWI), a regional-scale digital mapping and assessment project that began in 1986, I recall asking Rob about the data collection standards he was using, and whether the states and territories were supplying primary digital data, or if he was collecting it himself. His answers were somewhat surprising.

States and territories that supported the philosophy of the wilderness mapping project provided in-kind support to digitally capture the relevant datasets from printed documents. When digitised spatial data, such as road and track networks, forest management practices and watering points in rangelands, were not supplied, Rob developed them himself by collecting and analysing large amounts of primary digital data. Systematic and well organised, he then provided these data to the relevant jurisdictions.

It is worth noting that there was considerable debate at the time about the appropriateness of using the term 'wilderness', given past and current Indigenous occupation and management of Australia. It was also a time when most land management agencies were just beginning to embrace computers to analyse and store NRM data, and commencing the process of digitally converting paper maps and reports into computer-readable data formats.

It is worth considering some of the technical constraints that Rob faced, and his foresight in building an enduring data infrastructure that was designed to inform and influence future land use policies and planning concerning wilderness, its type, extent and modification states. Compared to what we have today, his operating environment was extremely clunky and primitive, to say the least. For example, GIS were command-driven; Rob's early adoption of GIS to collect, collate and store spatial data, and to assess the effects of land use on wilderness quality at a regional scale across Australia, was exemplary. His use of regional and national databases was essential, as these enabled him to operate consistently across jurisdictions at a regional scale. His applications of these awkward and 
cumbersome tools were recognised as exemplary by academic colleagues and those in government. Digitising was manual, slow and tedious. Metadata for spatial datasets was neither developed nor accepted as good practice; standards were neither defined nor adopted nationally-these took another 10 years. Yet, Rob meticulously documented these datasets. Printers were evolving from hexadecimal and symbol-based printing, but shades of grey were what was required. Rob was a pioneer in the use of GIS to present the big picture.

As the wilderness project progressed, so too did the power and sophistication of GIS and databases. Given the opportunity to migrate primary data from one platform to the next, Rob was quick to take advantage of developments in flexibility and interactivity (Lesslie, 2016; Lesslie \& Maslen, 1995). These developments, which allowed for improved analysis and visualisation of wilderness over large areas, enhanced the ability to understand regional issues and develop regional solutions.

The Multi-Criteria Analysis Shell for Spatial Decision Support (MCAS-S) tool represents the culmination of Rob's support for the efficient use of primary data across multiple projects over time (Lesslie, 2013; Lesslie et al., 2008). The MCAS-S has been widely used by government agencies, NRM groups, land use policy and planning researchers and agricultural scientists. The tool provides ready access to large quantities of environmental, social and economic information, and has straightforward analytical features. The MCAS-S helps decision-makers to understand and visualise the spatial and temporal patterns of their world, analyse biophysical and cultural interactions, quickly investigate patterns and processes and provide a full record of the decisions made.

\section{Use Conceptual Models to Represent Complex Eco-Social Systems}

Rob had a well-developed ability to synthesise disparate sources of data to produce novel insights into complex situations. The landscape we see today is the product of millennia of evolution and change, usually incorporating some level of human use and management. The human use of landscapes varies from intensive and localised to extensive and widespread. The frequency, duration and magnitude of the effects of human use are different in various ecosystems. Land managers employ a number of management practices to maintain or change the ecological function of native vegetation at site or landscape levels. This number 
increases when historic practices are added to the list of contemporary practices (Thackway \& Specht, 2015). Rob was cognisant of these complexities and often constructed conceptual models to convey concise and simple messages to decision-makers.

Rob's geographical training influenced his approach to communication. $\mathrm{He}$ concentrated on using spatial models and maps to provide clear visual information, and used real-world examples to illustrate the effects of land use on landscape patterns and processes. His research into eco-social systems - including pastoralism in the arid rangelands, managed production forests and intensively managed cropping and pastures - generated insights into the responses of ecosystems to different management regimes and threats. His breadth and depth of experience was highly valued by managers of policy and programs in considering the design and implementation of public programs to achieve good public policy outcomes.

As a result of his doctoral research, Rob was aware that those places that remained relatively remote and natural were becoming increasingly rare and more valuable as modern technological society extended its reach and impact across Australia (Lesslie, 2016). Wilderness is context dependent-it is relative. Defining wilderness quality as a continuum of remote and natural conditions, and using assessable units and a common scale, provides decision-makers with a solid conceptual foundation to approach the issue of identifying wilderness resources. It also provides a coherent evidence base for discussion and debate regarding wilderness more broadly-from concerns about its cultural context, through to measures for wilderness protection and management (Lesslie, 2016). This focus on remote and natural conditions enables decision-makers to quantify thresholds of interest and to visualise these as effects of modern technological societies in landscapes (i.e. patterns of land use and management, and settlement and access). The conceptual model for wilderness value is shown in Figure 2.1.

The capacity to represent this conceptual model as mapped spatial layers provides decision-makers with unprecedented opportunities to identify and track spatial and temporal changes in the type, extent and modification of wilderness (see Figure 2.2). Further, newly available data streams, including remotely sensed land cover data, digital topographic and terrain mapping and land use and dynamic vegetation, can be used to enhance the mapping of wilderness quality. 


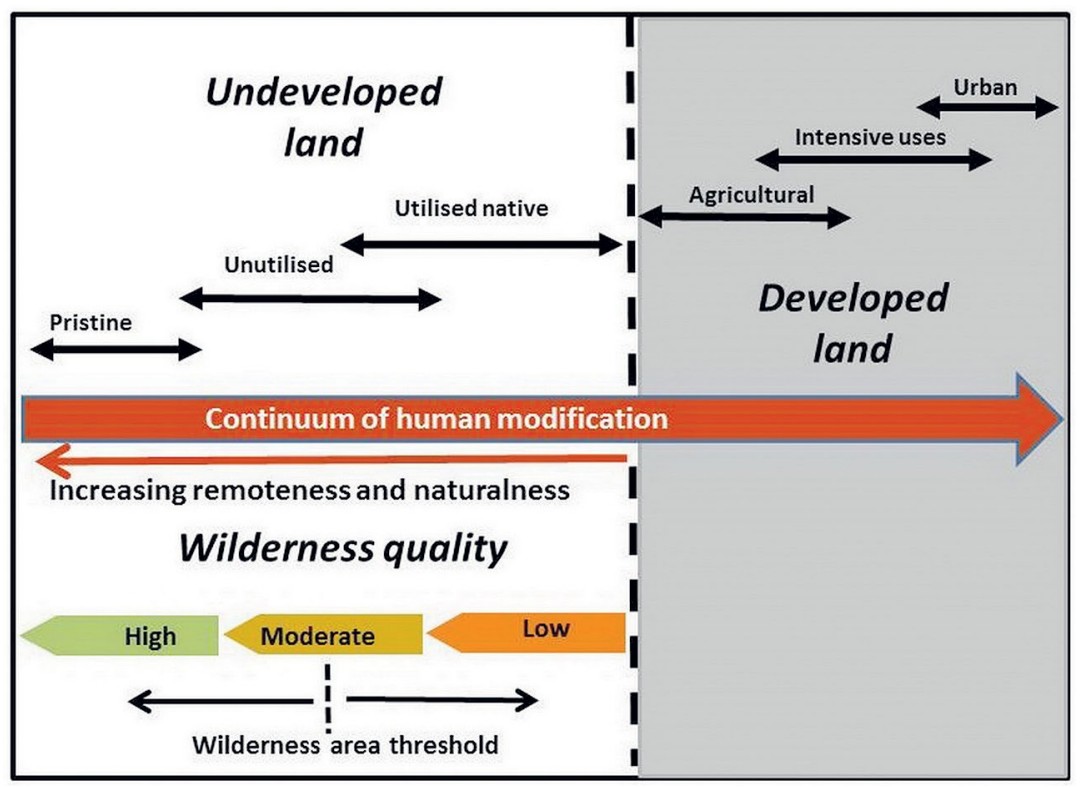

Figure 2.1: The wilderness continuum concept.

Source: Adapted from Lesslie \& Taylor (1985).

A similar conceptual model based on degrees of human modification of plant communities is the VAST framework (Lesslie, 2016). Maps produced representing this model inform decision-makers about the extent of native vegetation and changes in condition at regional and national levels (Thackway \& Lesslie, 2008). By combining maps of vegetation type (Department of the Environment and Water Resources, 2007 ) with the condition of vegetation (e.g. Figure 2.3), decision-makers gain powerful insights into setting national and regional priorities for the restoration and rehabilitation of highly modified landscapes (e.g. Yapp \& Thackway, 2015, Figure 7).

Figure 2.2 shows the distribution of wilderness quality across Australia based on the results of the ANWI (the survey was incomplete in far southwestern Australia) (Lesslie \& Maslen, 1995). The threshold at which 'wilderness' is recognised changes according to environmental context and over time. Figure 2.3 shows similar areas to those delineated as wilderness (Figure 2.2) using a set of area selection criteria and additional assessments to validate and revise the ANWI results (Department of Sustainability, Environment, Water, Population and Communities, 2008). 


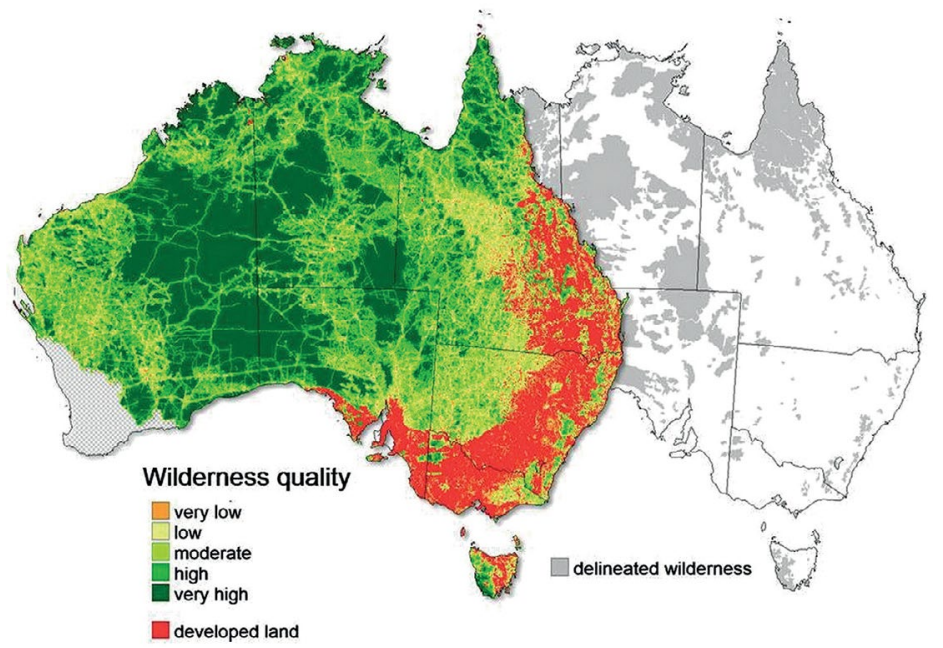

Figure 2.2: Wilderness quality and delineated wilderness in Australia, c. 1990.

Source: Lesslie (2016).

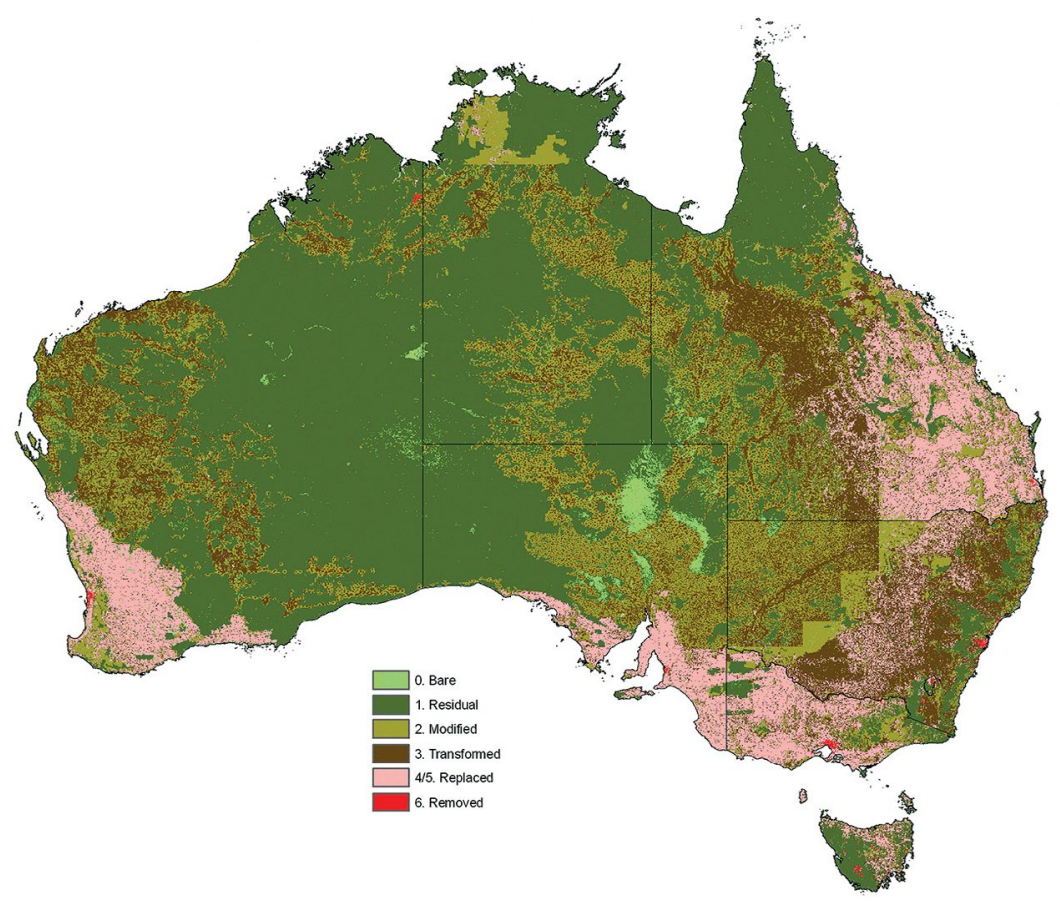

Figure 2.3: Vegetation assets, states and transitions (VAST) dataset for Australia (version 2.0).

Source: Lesslie, Thackway \& Smith (2010). 


\section{Be True to Your Core Principles}

Rob felt strongly that, in addition to the spatial, temporal scales in land use planning were vital. There is an imperative to move beyond the apparent current short-term political cycle that drives inappropriate resource management decisions to a longer-term intergenerational approach informed by the best available information (data) at a national level.

In 2007, Rob was a founding member of the ongoing Wilderness Society WildCountry Science Council (Mackey et al., 2007; Wilderness Society n.d.-a). This group has four pillars that represent recurring themes in Rob's life's work: ecological science, Indigenous conservation, climate change and economic development. One of the group's core values is to maintain and protect natural processes that sustain human wellbeing, biota and landscapes across the continent. Echoing the worldview that Rob espoused in his private life and public work, the Wilderness Society's (n.d.-b) vision is to transform Australia into a society that protects, respects and connects with the natural world that sustains us. The WildCountry Science Council's activities in promoting a whole-of-landscape approach, and focusing campaigns and policies on the importance of ecological connectivity at both regional and continental scales, also resonate with Rob's work on wilderness quality as a continuum to provide evidence for land use policy and planning.

Regrettably, Rob's involvement in the WildCountry Science Council was deemed incompatible with the roles and responsibilities of a public servant in the Australian Government. He resigned his membership of the council but continued to observe its work from a distance. It is worth noting that the formative work of this council provided the fundamental underpinning of the landscape connectivity movement that is now mainstream across regional Australia (Fitzsimons et al., 2013).

\section{Influence Future Leaders of Land Use and Planning Through Philanthropy}

A focus of Rob's last year of life was to work with his family in establishing a lasting philanthropic legacy to support future research and other land management activities at the Fenner School of Environment and Society at The Australian National University. Rob's aim was the promotion of long-term sustainable management and conservation of Australia's 
national landscapes and ecosystems. The Lesslie Endowment (n.d.) will provide support for research grants, scholarships, fellowships, prizes or public seminars and workshops.

\section{Acknowledgements}

Lynne Alexander, Jake Gillen and Graham Yapp provided helpful advice on the structure and content of an earlier draft.

\section{References}

ACLUMP (Australian Collaborative Land Use and Management Program). (2010). Land use and land management information for Australia: Workplan of the Australian Collaborative Land Use and Management Program. Canberra, ACT: Australian Bureau of Agricultural and Resource Economics and Sciences.

Department of the Environment and Water Resources. (2007). Australia's Native Vegetation: A summary of Australia's Major Vegetation Groups, 2007. Australian Government, Canberra, ACT.

Department of Sustainability, Environment, Water, Population and Communities. (2008). Remote and natural lands delineation. Retrieved from www.environment.gov.au/heritage/publications/anlr/ maps-delin.html

Fitzsimons, J., Pulsford, I. \& Wescott, G. (Eds.). (2013). Linking Australia's landscapes: Lessons and opportunities for large-scale conservation networks. Melbourne, VIC: CSIRO Publishing.

Lesslie Endowment. (n.d.). Retrieved from www.anu.edu.au/giving/ support-us/lesslie-endowment

Lesslie, R. (1997). A spatial analysis of human interference in terrestrial environments at landscape scales (Unpublished doctoral dissertation). The Australian National University, Canberra, ACT. 
Lesslie, R. (2013). Mapping our priorities—innovation in spatial decision support. In P. Figgis, J. Fitzsimons \& J. Irving (Eds.), Innovation for 21st century conservation (pp. 156-63). Sydney, NSW: Australian Committee for the International Union of Conservation of Nature.

Lesslie, R. (2016). The wilderness continuum concept and its application in Australia: Lessons for modern conservation. In S. Carver \& S. Fritz (Eds.), Mapping wilderness: Concepts, techniques and applications (pp. 22-40). New York, NY: Springer. doi.org/10.1007/978-94-0177399-7_2

Lesslie, R. G., Hill, M. J., Hill, P., Cresswell, H. P. \& Dawson, S. (2008). The application of a simple spatial multi-criteria analysis shell for natural resource management decision making. In C. Pettit, W. Cartwright, I. Bishop, K. Lowell, D. Pullar \& D. Duncan (Eds.), Landscape analysis and visualisation: Spatial models for natural resource management and planning (pp. 73-96). Berlin: Springer. doi.org/10.1007/978-3-54069168-6_5

Lesslie, R. G. \& Maslen, M. (1995). National wilderness inventory, Australia: Handbook of procedures, content and usage (2nd ed.). Canberra, ACT: Australian Heritage Commission.

Lesslie, R. G. \& Taylor, S. G. (1985). The wilderness continuum concept and its implications for Australian wilderness preservation policy. Biological Conservation, 32, 309-33.

Lesslie, R., Thackway, R. \& Smith, J. (2010). A national-level vegetation assets, states and transitions (VAST) dataset for Australia (version 2.0). Canberra, ACT: Bureau of Rural Sciences. Retrieved from data.daff.gov. au/data/warehouse/pe_brs90000004193/VASTv2Data_20100320_ ap14.pdf

Mackey, B. G., Soulé, M. E., Nix, H. A., Recher, H. F., Lesslie, R. G., Williams, J. E., ... Possingham, H. P. (2007). Applying landscapeecological principles to regional conservation: The WildCountry Project in Australia. In J. Wu \& R. J. Hobbs (Eds.), Key topics and perspectives in landscape ecology (pp. 192-213). Cambridge, UK: Cambridge University Press. 
NLWRA (National Land and Water Resources Audit). (2008). Land usestatus of information for reporting against indicators under the national resource management monitoring and evaluation framework. Canberra, ACT: National Land and Water Resources Audit.

Thackway, R. \& Lesslie, R. (2008). Describing and mapping humaninduced vegetation change in the Australian landscape. Environmental Management, 42, 572-90. doi.org/10.1007/s00267-008-9131-5

Thackway, R. \& Specht, A. (2015). Synthesising the effects of land use on natural and managed landscapes. Science of the Total Environment, 526, 136-52. doi.org/10.1016/j.scitotenv.2015.04.070

Wilderness Society. (n.d.-a). WildCountry related scientific publications. Retrieved from www.wilderness.org.au/wildcountry-related-scientificpublications\#sthash.H0Nv1SXY.dpuf

Wilderness Society. (n.d.-b). Ourpurpose. Retrieved from www.wilderness. org.au/our-vision

Yapp, G. A. \& Thackway, R. (2015). Responding to change—criteria and indicators for managing the transformation of vegetated landscapes to maintain or restore ecosystem diversity. In J. A. Blanco (Ed.), Biodiversity in ecosystems - linking structure and function. Retrieved from www.intechopen.com/books/biodiversity-in-ecosystems-linkingstructure-and-function/responding-to-change-criteria-and-indicatorsfor-managing-the-transformation-of-vegetated-landscapes 
This text is taken from Land Use in Australia: Past, Present and Future, edited by Richard Thackway, published 2018 by ANU eView, The Australian National University, Canberra, Australia.

doi.org/10.22459/LUA.02.2018.02 